\title{
Teaching in the Digital Galaxy: Study of Spanish Non-University Faculty According to the Common Framework for Teaching Digital Competence
}

\author{
Palacios-Rodríguez Antonio ${ }^{1}$ and Martín-Párraga Lorena ${ }^{2}$ \\ ${ }^{1,2}$ Universidad de Sevilla, Sevilla, Spain \\ 1aprodriguez@us.es, ${ }^{2}$ lorena@grupotecnologiaeducativa.es
}

\begin{abstract}
New advances in technologies make up one of the main premises of the 21 st century. Studies carried out highlight the importance of making good use of this type of technology to obtain positive results in its application. In the educational field, the need to possess skills that guarantee correct and effective use is emphasized. Due to these demands, the present work was born: the study of teaching competence, according to the Spanish Common Framework of Reference for Teaching Digital Competence, to solve the existing problems among teachers of different educational stages within the competence area of innovation and use of the digital technology. In it, the knowledge and use of these digital resources are shown, as well as the online teacher training and the innovation projects carried out. For this, a descriptive study was carried out on 233 non-university faculty submitted to a selfassessment questionnaire. The results show that the majority has a basic-intermediate level in the knowledge and use of classical technological resources and spaces. It is relevant as these present certain difficulties in more complex tasks. Due to this, it is proposed to start different lines of research, according to the training needs in Information and Communication Technology (ICT).
\end{abstract}

Keywords: Digital teaching competence, Digital competence, Teaching training, Nonuniversity education, Information and Communication Technology (ICT)

\section{Introduction}

In the current world in which we live, it is increasingly notable how the use of Information and Communication Technologies (ICT) is an essential engine of change in the economic and social development of what is known as the knowledge society. Tools adaptable to various functionalities, whose application runs between various fields, such as economic, social, political, and cultural, offering added value to our society. These new ways of understanding reality subjugate human behavior affirm that today's society is "hypertechnologized" [1]. In other words, a society is subjected to profound changes concerning the convergence of the different existing media and, among them, the technological ones.

It is to know how digital communication has managed to transform literacy practices, assuming its importance in the functioning of the work and recreational contexts of the 21 stcentury knowledge community [2]. Despite this, being immersed in the digital society is not

Article history:

Received (August 15, 2020), Review Result (September 24, 2020), Accepted (October 28, 2020) 
synonymous with equal opportunities, as well as its access and use, just as it does not ensure the development of such competition in a natural way. This conception can generate differences between society, visible at different levels of competencies, such as that of passive consumers (illiterate, lacking in technological and communication skills). That is why the need for citizenship to dominate their language, literacy, and competence is emphasized. Addressing the different causes that underlie digital gender disparities, presenting itself as essential, when developing equality and equity policies. At the same time, also highlight the importance of the following question: technology is not an agent of change in itself, but rather encompasses gender characteristics and interacts with social circumstances in complex ways [3] [4].

To support the foregoing, it has emphasized the role of European policies, which provide basic skills that highlight the essential role of ICT in the formation of citizenship, as well as the importance of integrating them into the world of work [5][6].

The Parliament and the Council of the European Union define the concept of digital competence as that which: involves the safe and critical use of the technologies of the information society for work, leisure, and communication [7]. Also, they endorse digital competence as one of the eight essential competencies to be developed at the end of compulsory education, so that it is successfully incorporated into society.

The European Union defines such competencies as a combination of knowledge, skills, and attitudes appropriate to the context [8], managing to provide common reference frameworks, oriented towards those responsible for the education system.

Therefore, it is affirmed that the ability to make use of technologies, to live, work and learn in the so-called knowledge society is considered essential in our days [9][10].

Therefore, the need arises, based on the aforementioned references, to have updated instruments, capable of offering validity and reliability to the study of said competence, and these must be adapted to the contexts in which it is intended to apply [11].

The interest of this work is linked to the application and study of the Common Framework of Spanish Teaching Digital Competence at a non-university level. Therefore, the research problem that arises is the following; What levels of digital competence exist in the innovation and use of digital technology that teachers present, in the educational stages of Infant, Primary and Secondary, based on the Common Framework of Teaching Digital Competence, according to the capacity for innovation and use of digital technology?

\section{Literature review}

New advances in digital technologies and the modernization of educational systems reflect problems related to the understanding and construction of knowledge with digital technologies. These problems evolve together with the development of technologies [12]. These accelerated changes demand new forms of understanding [13].

One of the reports presented by the European Commission, "Rethinking Education", advocates quality education in contexts of social transformation to adapt it to the current moment. The importance of taking advantage of and managing to effectively integrate technology in training centers is highlighted. In the same way, it proposes to be able to develop education plans at the international level with the main purpose of increasing the quality of the professional capacities of citizens [14]. The effective incorporation of digital competence in the educational system through proper quality training of teachers is also defended. Therefore, it becomes clear that this last element, "teacher training in ICT", is one of the most significant for the development of educational systems. That is why it is presented 
as essential to be able to implement digital literacy in teaching with the mastery of ICT, as well as its integration in the teaching/learning processes [15] [16]. In short, Information and Communication Technologies constitute an essential role as a resource for teachers, where the level of digital competence will be crucial, to give quality to the educational process [17].

In 2012, as part of the School Culture Plan and the Strategic Framework for Teacher Professional Development, the project for the "Common Framework for Teaching Digital Competence" appears within the National Institute of Educational Technologies and Teacher Training (INTEF); an institution belonging to the Spanish Ministry of Education, Culture and Sports. Its main objective is to be able to establish a model for the development of digital skills for teachers aligned with the European Framework in its different dimensions and levels [18]. Therefore, it forms a general reference framework to support the development of training, evaluation, and certification processes for teachers at all levels [19] [20].

\section{Methodology}

\subsection{Objectives}

With the main purpose of offering viable answers to the aforementioned problem, a single general objective is proposed; being specified in specific objectives, from which the following hypotheses derive:

The general objective pursued by this study is to be able to know the level of digital competence in innovation and use of digital technologies of teachers at different educational levels based on the Common Framework of Digital Competence Teacher. Therefore, the objective aims are to be able to develop instruments for the collection of valid and reliable data that guarantee the measurement of the digital competence of teachers in innovation and use of digital technologies. It focuses on the recognition of the degree of knowledge and use of such resources, as well as the degree of involvement in online training and innovation projects. On the other hand, to know the degree and type of digital competence of the teachers, in Early Childhood, Primary and Secondary educational stages, related to the knowledge and use of digital resources, involvement in online teacher training and innovation projects.

\subsection{Design}

A descriptive study is proposed taking into account the voluntary participation of teachers from a total of 4 Spanish public centers ( 2 centers for Infant and Primary Education and 2 in Compulsory Secondary Education / Baccalaureate / Vocational Training), who answer a selfassessment questionnaire with scaling, Likert type (1. Not at all, 2. Very little, 3. Little, 4. Somewhat, 5. Quite a bit and 6. A lot). This data collection technique has been refined in previous sessions of expert tutorials and analyzed with Statistical Package for the Social Sciences (SPSS). For this, it is chosen to apply descriptive analysis. With this design, it is not intended to modify the variables, object of study, but to explore their nature and behavior in the analyzed sample.

Also, the negotiation process data collection is democratic, flexible, written, and slow (respect the times set in the time planning). 


\subsection{Sample}

The study has a sample of 233 teachers distributed among the aforementioned educational centers. For their selection, incidental or convenience criteria were chosen, according to their availability to answer the questionnaire. All participants were contacted via corporate email. In this way, the validity of the data is ensured. A total of 450 emails were sent, of which 233 $(51.8 \%)$ responses were obtained.

The mean age of this sample oscillates in the 45 years, with a greater concentration of participants in ages between 31-50 years. Also, taking into account the relationship of the years of service in the position, the average number of teachers is 16.

\subsection{Instruments}

For data collection, the implementation of a questionnaire [Table 1] based on the Common Framework for Digital Competence is chosen Teacher (8). The different items shown have been improved in the different sessions with experts, managing to respond to the three competency dimensions that are intended to be evaluated: level of knowledge and use of digital resources (12), level of involvement in online training (12) and level of involvement in collaborative digital teaching innovation projects (7).

Table 1. Description of the items in the questionnaire

\begin{tabular}{|c|c|c|c|c|}
\hline ITEM & DIMENSION & DESCRIPTOR & INDICATOR & LEVEL \\
\hline A1 & Digital resources & $\begin{array}{l}\text { Known within the } \\
\text { educational field. }\end{array}$ & Classic resources & A1 \\
\hline $\mathrm{A} 2$ & Digital resources & Use in class. & Classic resources & $\mathrm{A} 2$ \\
\hline A3 & Digital resources & Create for students. & Classic resources & $\mathrm{B} 1$ \\
\hline A4 & Digital resources & $\begin{array}{l}\text { Use to show students' } \\
\text { work. }\end{array}$ & Classic resources & B2 \\
\hline A5 & Digital resources & Create collaboratively. & Classic resources & $\widehat{A}$ \\
\hline A6 & Digital resources & Share. & Classic resources. & $\mathrm{C} 2$ \\
\hline A7 & Digital resources & $\begin{array}{l}\text { Known within the } \\
\text { educational field. }\end{array}$ & Innovative resources. & A1 \\
\hline A8 & Digital resources & Use in class. & Innovative resources. & $\mathrm{A} 2$ \\
\hline A9 & Digital resources & Create for students. & Innovative resources. & B1 \\
\hline A10 & Digital resources & $\begin{array}{l}\text { Use to show the work of } \\
\text { the students. }\end{array}$ & Innovative resources. & B2 \\
\hline A11 & Digital resources & Create collaboratively. & Innovative resources. & $\mathrm{C} 1$ \\
\hline A12 & Digital resources & Share. & Innovative resources. & $\mathrm{C} 2$ \\
\hline B13 & Digital resources & $\begin{array}{l}\text { Known within the } \\
\text { educational field. }\end{array}$ & Classic online training spaces. & A1 \\
\hline B14 & Digital resources & Participate. & Classic online training spaces. & A2 \\
\hline B15 & Online teacher training & Use to find solutions. & Classic online training spaces. & B1 \\
\hline B16 & Online teacher training & $\begin{array}{c}\text { Create educational } \\
\text { experiences. }\end{array}$ & Classic online training spaces. & B2 \\
\hline B17 & Online teacher training & $\begin{array}{c}\text { Encourage the } \\
\text { participation of the } \\
\text { educational community. }\end{array}$ & Classic online training spaces. & $\mathrm{C} 1$ \\
\hline B18 & Online teacher training & Train other classmates. & Classic online training spaces. & $\mathrm{C} 2$ \\
\hline B19 & Online teacher training & $\begin{array}{l}\text { Known within the } \\
\text { educational field. }\end{array}$ & $\begin{array}{l}\text { Innovative online training } \\
\text { spaces. }\end{array}$ & A1 \\
\hline B20 & Online teacher training. & Take part. & $\begin{array}{l}\text { Innovative online training } \\
\text { spaces. }\end{array}$ & $\mathrm{A} 2$ \\
\hline B21 & Online teacher training & Use to find solutions. & $\begin{array}{l}\text { Innovative online training } \\
\text { spaces. }\end{array}$ & B1 \\
\hline
\end{tabular}




\begin{tabular}{|c|c|c|c|c|}
\hline B22 & Online teacher training & $\begin{array}{c}\text { Create educational } \\
\text { experiences. }\end{array}$ & $\begin{array}{l}\text { Innovative online training } \\
\text { spaces. }\end{array}$ & B2 \\
\hline B23 & Online teacher training & $\begin{array}{c}\text { Encourage the } \\
\text { participation of the } \\
\text { educational community. }\end{array}$ & $\begin{array}{l}\text { Innovative online training } \\
\text { spaces. }\end{array}$ & $\mathrm{C} 1$ \\
\hline B24 & Online teacher training & Train other classmates. & $\begin{array}{l}\text { Innovative online training } \\
\text { spaces. }\end{array}$ & $\mathrm{C} 2$ \\
\hline $\mathrm{C} 25$ & $\begin{array}{c}\text { Digital collaborative } \\
\text { teaching innovation } \\
\text { projects. }\end{array}$ & Know. & Activities. & A1 \\
\hline $\mathrm{C} 26$ & $\begin{array}{c}\text { Digital collaborative } \\
\text { teaching innovation } \\
\text { projects. }\end{array}$ & Use related activities. & Activities. & $\mathrm{A} 2$ \\
\hline $\mathrm{C} 27$ & $\begin{array}{l}\text { Collaborative teaching } \\
\text { innovation projects }\end{array}$ & $\begin{array}{c}\text { Digital collaborative } \\
\text { teaching innovation } \\
\text { projects. }\end{array}$ & Participate individually. & B1 \\
\hline $\mathrm{C} 28$ & $\begin{array}{l}\text { Collaborative teaching } \\
\text { innovation projects }\end{array}$ & $\begin{array}{c}\text { Digital collaborative } \\
\text { teaching innovation } \\
\text { projects. }\end{array}$ & Participate cooperatively. & B2 \\
\hline C29 & $\begin{array}{l}\text { Collaborative teaching } \\
\text { innovation projects }\end{array}$ & $\begin{array}{c}\text { Digital collaborative } \\
\text { teaching innovation } \\
\text { projects. }\end{array}$ & $\begin{array}{l}\text { Inform the educational } \\
\text { community. }\end{array}$ & B2 \\
\hline C30 & $\begin{array}{l}\text { Collaborative teaching } \\
\text { innovation projects }\end{array}$ & $\begin{array}{c}\text { Digital collaborative } \\
\text { teaching innovation } \\
\text { projects. }\end{array}$ & $\begin{array}{l}\text { Promote participation of the } \\
\text { educational community. }\end{array}$ & $\mathrm{C} 1$ \\
\hline C31 & $\begin{array}{l}\text { Collaborative teaching } \\
\text { innovation projects }\end{array}$ & $\begin{array}{c}\text { Digital collaborative } \\
\text { teaching innovation } \\
\text { projects. }\end{array}$ & $\begin{array}{c}\text { Collaboratively generate } \\
\text { knowledge }\end{array}$ & $\mathrm{C} 2$ \\
\hline
\end{tabular}

The questionnaire includes a small heading where the main objective pursued in the evaluation is presented. Subsequently, identification data is collected: sex, age, years of teaching, and educational level where the class is taught. Once completed, an email is provided for participants who are interested in receiving the results of said evaluation.

\section{Results}

\subsection{Reliability}

To measure the reliability of the questionnaire, the Cronbach's alpha coefficient is used in its entirety. These results show high reliability of the questionnaire with a Cronbach's alpha coefficient of 0.936 . Furthermore, the homogeneity of the coefficient of each item must be highlighted as acceptable, with a mean correlation of 0.756 .

\subsection{Digital resources}

The results obtained in the "digital resources" dimension are shown in [Table 2]. High dispersion is observed in said data, that is, high response diversity. This statement is reinforced with the standard deviation (all close to 1.5), variance (between 1 and 3), range (between 4 and 5), minimum (1- None or 2- Very little, depending on the item), and a maximum (6-A lot). With the central tendency and the distribution of the data, it can be observed how there are notable differences between the mean scores of each factor. Thus, the median of the responses for the first factor (basic-intermediate level of creation and use of classic digital resources) is between 4-Somewhat and 5-Quite a bit; the second factor (basicintermediate level of creation and use of innovative digital resources) between 3-Little and 4Somewhat and the third factor (advanced level of creation and use of digital resources) 2- 
Very little. This phenomenon can be corroborated by analyzing the existing asymmetry and kurtosis between the factors. In each of the cases, the distribution is asymmetric. The grouping of the data is distributed according to the level: greater grouping in favor of 6-Much, 5-Quite a bit and 4-Somewhat for the first factor, 4-Somewhat, 3-Little and 2-Very little for the second factor and 3-Little, 2-Very little and 1-Nothing for the third factor.

Table 2. Descriptive statistics dimension "digital resources"

\begin{tabular}{|c|c|c|c|c|c|c|c|c|c|}
\hline Item & $\mathrm{A} 1$ & $\mathrm{~A} 2$ & $\mathrm{~A} 3$ & $\mathrm{~A} 7$ & $\mathrm{~A} 9$ & $\mathrm{~A} 10$ & $\mathrm{~A} 5$ & $\mathrm{~A} 11$ & $\mathrm{~A} 12$ \\
\hline Average & 4.82 & 4.59 & 3.75 & 4.24 & 2.68 & 2.85 & 2.14 & 2.16 & 2.39 \\
\hline Median & 5.00 & 5.00 & 4.00 & 4.00 & 3.00 & 3.00 & 2.00 & 1.00 & 2.00 \\
\hline Mode & 5 & 5 & 5 & 5 & 1 & 1 & 1 & 1 & 1 \\
\hline $\begin{array}{c}\text { Standard } \\
\text { deviation }\end{array}$ & 1.052 & 1.046 & 1.594 & 1.352 & 1.752 & 1.614 & 1.296 & 1.543 & 1.633 \\
\hline Variance & 1.107 & 1.094 & 2.541 & 1.828 & 3.071 & 2.606 & 1.679 & 2.382 & 2.666 \\
\hline
\end{tabular}

The results detail that the majority of teachers have a basic-intermediate level of creation and use of classic digital resources, they know (item A1) and use in class (item A2). To a lesser extent, teachers have a basic-intermediate level when creating and using innovative resources, highlighting their high knowledge of them (item A7), as well as their little use in class (items A8 and A9). Regarding the advanced level of creation and use of digital resources, most stand out for their little or even no ability to create them cooperatively (items A5 and A11) or share them with other teachers (item A12).

\subsection{Online teacher training}

The results obtained in the dimension "online teacher training" can be seen in [Table 3], with a smaller dispersion of the data than the previous one, that is, there is not so much diversity in the response. The standard deviation comprising the fourth and fifth factors (basic-intermediate level of involvement in classic online training spaces and basicintermediate level of involvement in innovative online training spaces, respectively) are close to 1.5; the variance of the sixth factor (advanced level of involvement in online training spaces) is low (close to 0.8). The ranges of these items oscillate between 4 and 5, except for item B24 (3). In the central tendency and the distribution of the data, notable differences are observed between the mean scores of each factor. The median of the responses to the fourth factor is between 5-Quite a bit and 4-Somewhat and the fifth and sixth factor 1-Not at all. Thanks to this phenomenon, the analysis of the symmetry and kurtosis of the factors can be corroborated. In all cases, the distribution is asymmetric, with a grouping of data that is distributed depending on the level: greater grouping in favor of 6-Much, 5-Quite a bit, and 4Somewhat for the fourth factor; 2-Very little and 1-Nothing for the fifth factor and 1-Nothing for the sixth factor.

Table 3. Descriptive statistics dimension "online teacher training"

\begin{tabular}{|c|c|c|c|c|c|c|c|c|c|}
\hline Item & B13 & B14 & B15 & B16 & B19 & B21 & B22 & B23 & B18 \\
\hline Average & 4.32 & 3.46 & 3.46 & 3.18 & 2.26 & 1.80 & 1.87 & 1.65 & 1.38 \\
\hline Median & 5.00 & 4.00 & 4.00 & 4.00 & 1.00 & 1.00 & 1.00 & 1.00 & 1.00 \\
\hline Mode & 5 & 4 & 4 & 1 & 1 & 1 & 1 & 1 & 1 \\
\hline Standard deviation & 1.352 & 1.597 & 1.625 & 1.652 & 1.704 & 1.358 & 1.417 & 1.234 & .935 \\
\hline Variance & 1.829 & 2.551 & 2.640 & 2.730 & 2.904 & 1.844 & 2.009 & 1.522 & .874 \\
\hline
\end{tabular}


The results obtained affirm that the vast majority of teachers have a basic-intermediate level of involvement in the spaces for online training: they know them to a greater extent (item B13) and to a lesser extent they participate (item B14), they use them to search for solutions (item B15) and create educational experiences with them (item B16). Overall, half of the teachers failed to reach the basic-intermediate level of involvement in these innovative online training spaces: most are unaware of them (item B19), they do not participate in them (items B19, B20, B21); only a small percentage knows about them (item B19) and, to a lesser extent, about their involvement (items B19, B20, B21). Regarding the advanced level of involvement in these training spaces, most teachers deny having trained other teachers in this type of training space (items B18 and B24).

\subsection{Digital collaborative teaching innovation projects}

[Table 4] shows the descriptive analysis of the data collected from the dimension "digital collaborative teaching innovation projects". The dispersion obtained in the data is the same as the previous one, that is, there is lower diversity of response to the dimension of "digital resources". Regarding the standard deviation of the seventh factor, the intermediate basic level of involvement in digital collaborative teaching innovation projects, is around 1.25, and that of the eighth, intermediate-advanced level of involvement in digital collaborative teaching innovation projects, with the lowest score of all factors, 0.85. The data of the variances are similar, being high in the seventh factor and low in the eighth. The range of the items, in each one of the cases, is 4 points. In reference to the relationship between the central tendency and the distribution of the data, significant differences are again observed between the medians of the responses of each of them. The median of the seventh factor is between 2Very little and 1-Nothing and that of the eighth in 1-Nothing. Through the analysis of the asymmetry and the kurtosis of the factors, this phenomenon can be corroborated. In each of the cases, the asymmetry distribution, with a grouping of data, is distributed depending on the level: greater grouping in favor of 3-Little, 2- Very little and 1-Nothing for the seventh factor, and 2-Very little and 1-Nothing for the eighth factor.

Table 4. Descriptive statistics dimension "digital collaborative teaching innovation projects"

\begin{tabular}{|c|c|c|c|c|c|c|}
\hline Item & C25 & C26 & C27 & C29 & C30 & C31 \\
\hline Mean & 2.40 & 1.85 & 1.86 & 1.46 & 1.42 & 1.47 \\
\hline Median & 2.00 & 1.00 & 1.00 & 1.00 & 1.00 & 1.00 \\
\hline Mode & 1 & 1 & 1 & 1 & 1 & 1 \\
\hline Standard deviation & 1.400 & 1.107 & 1.211 & .894 & .840 & .864 \\
\hline Variance & 1.960 & 1.225 & 1.467 & .800 & .706 & .747 \\
\hline
\end{tabular}

The data show that most teachers have a basic-intermediate level of involvement in teaching innovation projects, and a lower level in the previous basic-intermediate levels: half of the respondents say they know them and participate somewhat, little or very little (items $\mathrm{C} 25, \mathrm{C} 26$, and C27); the other half don't even know them. All the teachers, as a whole, fail to reach intermediate-advanced levels of involvement in digital collaborative teaching innovation projects; nor do they promote them (item C29), nor do they promote the participation of their educational community (item C30) and they do not generate knowledge from them (C31). 


\section{Discussion}

Regarding the application and study of the INTEF model in schools, substantial information is offered, managing to respond to the research problem raised in said work. What are the levels of digital competence in innovation and use of digital technology that presents the teachers of Infant, Primary and Secondary Education, based on the Common Framework of Teaching Digital Competence, according to their capacity for innovation and use of digital technology?

Therefore, it would be a question of unifying the information obtained by the previous three, including, also, the levels of competencies that predominate in the sample under study, marking a decreasing order of predominance based on its median, these being: basicintermediate of creation and use of classic digital resources (5-Pretty), basic-intermediate of involvement in classic online training spaces (4-Something), basic-intermediate of creation and use of innovative digital resources (3-Little), advanced of creation and use of digital resources (2-Very little), basic-intermediate of involvement in innovative online training spaces (1-Nothing), basic-intermediate of involvement in digital collaborative teaching innovation projects (1-Nothing), intermediate-advanced involvement in digital collaborative teaching innovation projects (1-Nothing) and advanced involvement in online training spaces (1-Nothing).

Consequently, it can be considered that there are significant differences in the levels of competence in the different dimensions previously analyzed: use of digital resources, involvement in online teacher training, and involvement in innovation projects.

The results suggest that teachers present basic-intermediate levels of digital competence, predominating elementary competencies (knowing and participating) over more advanced ones (collaborating, sharing, generating knowledge ...) in, above all, traditional digital resources and spaces. A small percentage of the teaching staff shows an advanced level. At this level, instrumental competencies predominate, those that are related to the knowledge and use of digital resources, leaving at lower levels the involvement in online training and their participation in collaborative training projects.

These results present some similarity to those of previous research on digital competencies possessed by teachers of the XXI century [4] [19]. Studies confirm that the most extended level of competencies is not sufficient to achieve the successful integration of ICT in schools (medium-low level of competence). In the same way, these investigations show greater use of technologies as a means of exposure (knowledge and basic use) and as a tool that manages to generate new knowledge from an exchange in communication. As the results show, the studies that place future teachers at the highest levels of digital competence do so in relation to the domain of digital technology and the use of classic digital resources [21].

One of the main ways of explaining the low-level present in teachers, with digital competence, can be found related to their attitude to technologies. Its acceptance or rejection is conditioned, to a large extent, by its ability to incorporate it into the classroom [22][23]. The behavior of ICT in educational contexts depends on what the teacher can do with them and on his faculty to adapt them to the educational problems he wishes to solve, adapting to the context of the students [21]. That is why solid, stable, and quality models of training in digital competence are demanded, such as the Common Framework for Teaching Digital Competence. These proposals should serve not only to diagnose but also to improve the digital competence of teachers [24][25]. Thus, if it is diagnosed, the necessary tools can be provided with greater accuracy so that teachers can develop new skills that can be used in the classroom, thus improving educational quality. 


\section{Conclusions}

The results obtained in this research offer knowledge related to the level of digital competencies in innovation and use of digital technologies of the teachers of Early Childhood, Primary and Secondary Education of the educational centers, object of study, based on the Common Framework of Digital Competence Teacher. Thanks to the development of a reliable data collection instrument, it has been possible to measure teaching digital competence: the degree of knowledge and use of digital resources, the degree of involvement in online teacher training, and the degree of involvement in innovation projects. Similarly, this research has managed to contribute to the validation of the scales proposed by the Common Framework for Teaching Digital Competence [18]. Specifically, within the "problem solving" area of competence. In this sense, the reliability of the instrument created for this research allows the generation of scientific knowledge with a level of precision and valid evidence for the improvement of educational quality in training institutions.

The model analyzed supposes a transformation of the traditional communication, educational and work structures, methods, and assumptions. Therefore, how the training of citizenship is proposed for an authentic development of competence in accordance with the Knowledge Society must be rethought. All this through different levels and, therefore, as constant learning that mobilizes different dimensions of competence that go from the technical domain to innovation with digital technology.

One of the main limitations to studies has been found in the sample size, achieving more specific and representative results of the study population. Furthermore, the improvement of these items and their construct analysis, starting from a structural diagram of the model, through structural equations, will allow us to obtain higher levels of precision. The results obtained are characteristic of a specific population, therefore, it is necessary to contrast with populations that present similar characteristics to take them as definitive and descriptive of said educational communities.

It is considered essential to expand the study sample taking into account the characteristics of the population. Also, the need arises to reformulate some of the items to subsequently confirm the analysis of their validity, with a sample independent from the one studied. In this way, greater precision and scientific rigor are ensured.

On the other hand, from this research different lines of research may emerge focused on:

(1) Validation of skills assessment tools using solid and stable models.

(2) Carry out comparative studies between different contexts.

(3) Discover and contextualize the degree of digital competence in different European and international contexts.

(4) Identify digital gaps between different groups.

(5) Analyze and propose training actions at different levels (micro, meso, and macro) that favour the development of skills.

In short, this research serves as a model and basis for future studies on digital teaching competence, which will provide a vision of active teachers in Early Childhood Education, Primary Education, Compulsory Secondary Education, Baccalaureate, and Vocational Training, and may be comparable with populations that present characteristics Similar. The analysis and the results support the necessary structuring of the training actions, in such a way that they adjust to the reality of the centers and are directed towards increasing the competence level of the teaching staff through specific training plans. 
Teaching in the Digital Galaxy: Study of Spanish Non-University Faculty According to the Common Framework for Teaching Digital Competence

\section{References}

[1] J. Pérez, T. Tapio, V. Jose, M. Pérez, and T. Varis, TT, "Media literacy and new humanism," UNESCO Institute for Information Technologies in Education, (2010)

[2] K. Mills, "A review of the "digital turn" in the new literacy studies," Review of Educational Research, vol.80, no.2, pp.246-271, (2010) DOI: 10.3102/0034654310364401

[3] R. Barragán-Sánchez, C. Corujo-Vélez, A. Palacios-Rodríguez and P. Román-Graván, “Teaching digital competence and eco-responsible use of technologies: Development and validation of a scale," Sustainability, vol. 12, no.18, pp.7721, (2020) DOI: 10.3390/su12187721

[4] R. Romero-Tena, R. Barragán-Sánchez, C. Llorente-Cejudo and A. Palacios-Rodríguez, "The challenge of initial training for early childhood teachers. A cross-sectional study of their digital competencies," Sustainability, vol.12, no.11, pp.4782, (2020) DOI: 10.3390/su12114782

[5] Council of the European Union, "Table conclusions. Brussels European council of march 20 and 21, 2003," Brussels, Publications Office of the European Union, (2003)

[6] Commission of the European Communities, "Education and training 2010. Reforms are urgently needed to successfully complete the Lisbon strategy," Lisbon, Publications Office of the European Union, (2003)

[7] Council of the European Union, "Recommendation of the European parliament and of the council of 18 December 2006 on key competences for lifelong learning," Brussels, Official Journal of the European Union, (2006)

[8] Council of the European Union, "Council recommendation of 22 may 2018 on key competences for lifelong learning," Brussels, Official Journal of the European Union, (2018)

[9] J. Cabero-Almenara and A. Palacios-Rodríguez, "European framework for digital teaching competence «DigCompEdu». Translation and adaptation of the «DigCompEdu check-in» questionnaire," Edmetic, vol.9, no.1, pp.213-234, (2020), DOI:10.21071/edmetic.v9i1.12462

[10] J. Cabero-Almenara, J. Barroso-Osuna, A. Palacios-Rodríguez, A. and C. Llorente-Cejudo, "Digital competences frameworks for university teachers: Their evaluation through the expert competence coefficient," Interuniversity Electronic Journal of Teacher Training, vol.23, no.2, (2020), DOI: 10.6018/reifop.413601

[11] E. Porat, I. Blau, I. and A. Barak, "Measuring digital literacies: Junior high school students' perceived competencies versus actual performance," Computers \& Education, vol.126, no.2, pp.23-36, (2018), DOI: 10.1016/J.COMPEDU.2018.06.030

[12] S. Kluzer, L. Pujol Priego, S. Carretero, Y. Punie, R. Vuorikari and M. Cabrera, "DigComp into action, get inspired make it happen a user guide to the European digital competence framework," Seville, JRC, (2018)

[13] A. Ruiz Cabezas, M. Medina Domínguez, E. Pérez Navío and A. Medina Rivilla, "University teachers' training: The digital competence," Pixel-Bit. Media and Education Magazine, vol.58, pp.181-215, (2020) DOI: $10.12795 /$ pixelbit.74676

[14] European Commission, "A new concept of education: Investing in skills to achieve better socio-economic results," Brussels, Publications Office of the European Union, (2012)

[15] O. Hatlevik, I. Throndsen, M. Loi and G. Gudmundsdottir, "Students' ICT self-efficacy and computer and information literacy: Determinants and relationships," Computers \& Education, vol.118, pp.107-119, (2018) DOI: 10.1016/J.COMPEDU.2017.11.011

[16] R. Roig-Vila, S. Mengual-Andrés and P. Quinto-Medrano, "Technological, pedagogical and disciplinary knowledge of Primary school teachers," Comunicar, vol.45, no 23, pp.151-159, (2015) DOI: 10.3916/C452015-16

[17] J. Salinas, "Teaching innovation and use of ICT in university teaching," University and Knowledge Society Magazine, vol.1, no.1, pp.1-16, (2004)

[18] INTEF, "Common framework for teaching digital competence," Madrid, National Institute of Educational Technologies and Teacher Training, (2017) 
[19] J. Cabero-Almenara, R. Romero-Tena and A. Palacios-Rodríguez, "Evaluation of teacher digital competence frameworks through expert judgment: The use of the expert competence coefficient," Journal of New Approaches in Educational Research, vol.9, no.2, pp.275-293, (2020) DOI: 10.7821/naer.2020.7.578

[20] J. Cabero-Almenara, R. Romero-Tena, J. Barroso-Osuna, and A. Palacios-Rodríguez, "Teaching digital skills frameworks and their adaptation to university and non-university teaching staff," Caribbean Journal of Educational Research (RECIE), vol.4, no.2, pp.137-158, (2020) DOI: 10.32541/recie.2020.v4i2.pp137-158

[21] J. Barroso-Osuna, "Teacher training in ICT: TPACK model”, Seville, Seville University, (2014)

[22] D. Bullock, "Moving from theory to practice: An examination of the factors that preservice teachers encounter as the attempt to gain experience teaching with technology during field placement experiences," Journal of Technology and Teacher Education, vol.12, no.2, pp.211-237, (2004)

[23] E. Ferrero de Lucas and I. Cantón Mayo, "Perception about the influence of ICT tools on knowledge management processes in grade of primary education," Pixel-Bit. Media and Education Magazine, vol.59, pp.65-96, (2020) DOI: 10.12795/pixelbit.75070

[24] F. Recio Muñoz, J. Silva Quiroz, and N. Abricot Marchant, "Analysis of digital competence in the initial training of university students: A meta-analysis study in the web of science", Pixel-Bit. Media and Education Magazine, vol.59, pp.125-146, (2020) DOI: 10.12795/pixelbit.77759

[25] A. Ruiz Mezcua, "Digital competence and ICTs in interpretation: «renew or die»". EDMETIC, vol.8, no.1, pp.55-71, (2019), DOI: 10.21071/edmetic.v8i1.11062

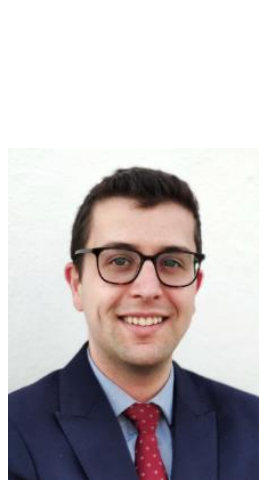

\section{Authors}

\section{Antonio Palacios-Rodríguez}

Graduated in Primary Education (English language) and Master in Management, Evaluation and Quality of Training Institutions. He is a member of the Didactic Research Group (GID-HUM 390): Technological and Qualitative Analysis. He currently works in the Department of Didactics and Educational Organization of the Faculty of Education Sciences, University of Seville. His teaching and research experience is related to Educational Technology and teacher training.

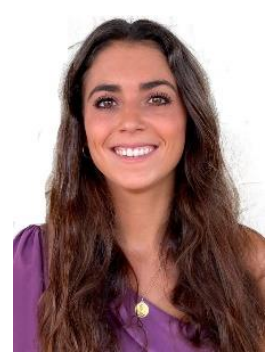

\section{Lorena Martín-Párraga}

Graduated in Pedagogy at the University of Seville. She is a collaborator of the Didactic Research Group (GID-HUM 390): Technological and Qualitative Analysis. Her teaching and research experience is related to Educational Technology and teacher training. 
Teaching in the Digital Galaxy: Study of Spanish Non-University Faculty According to the Common Framework for Teaching Digital Competence

This page is empty by intention. 